\title{
War of words erupts over fossil dig
}

The Olduvai Gorge, perhaps the most famous location in palaeoanthropology, has become a battleground for two research groups. Last week the rivals met to resolve their differences, but tensions remain high.

The Tanzanian site in question is where, in 1959, Mary Leakey found the first skull of the species Paranthropus boisei. The following year, the Leakey team returned to find the first fossils of Homo habilis. The discoveries at Olduvai encouraged researchers to follow the course of Africa's Great Rift Valley up through Kenya and Ethiopia, where a host of new human relations were found in subsequent decades.

Numerous teams have tried to pin down the relationships between the bones and artefacts, and to piece together a sense of the lives the various species led two million years ago. For 18 years, the Olduvai Landscape Paleoanthropology Project (OLAPP) - led by anthropologist Robert Blumenschine of Rutgers University in New Brunswick, New Jersey, archaeologist Fidelis Masao of the University of Dar es Salaam and Jackson Njau, principal curator at Tanzania's National Natural History Museum in Arusha - has collected plant and animal specimens to learn how these early relatives of man lived in the region (R. J. Blumenschine et al. Science 299, 1217-1221; 2003).

Last summer, the OLAPP team was distressed to learn that Tanzanian officials had issued permits to a group led by Manuel Domínguez-Rodrigo, of Complutense University in Madrid, and Audauz Mabulla, of the University of Dar es Salaam, to dig within the OLAPP region. The OLAPP researchers then found the competing group a kilometre away from their campsite, probing trenches the OLAPP team had dug near the bed where Leakey uncovered 'Zinj', the original P. boisei skull.

\section{"The situation is} awkward for both groups."

In general, researchers like to collect material in a standardized way. If a new group disturbs a site, it can harm the previous team's study if, for example, different collection techniques are used. The OLAPP team objected to the Tanzanian authorities and the Domínguez-Rodrigo/ Mabulla excavation was stopped.

This prompted an angry response from Domínguez-Rodrigo and Mabulla on the website of the Cultural Association for the Study of the Quaternary in the Cantabrian Region (www.accuca.conectia.es). Domínguez-Rodrigo also attacked the OLAPP group in newspaper articles in Madrid and Dar es Salaam. On the website, Domínguez-Rodrigo and Mabulla

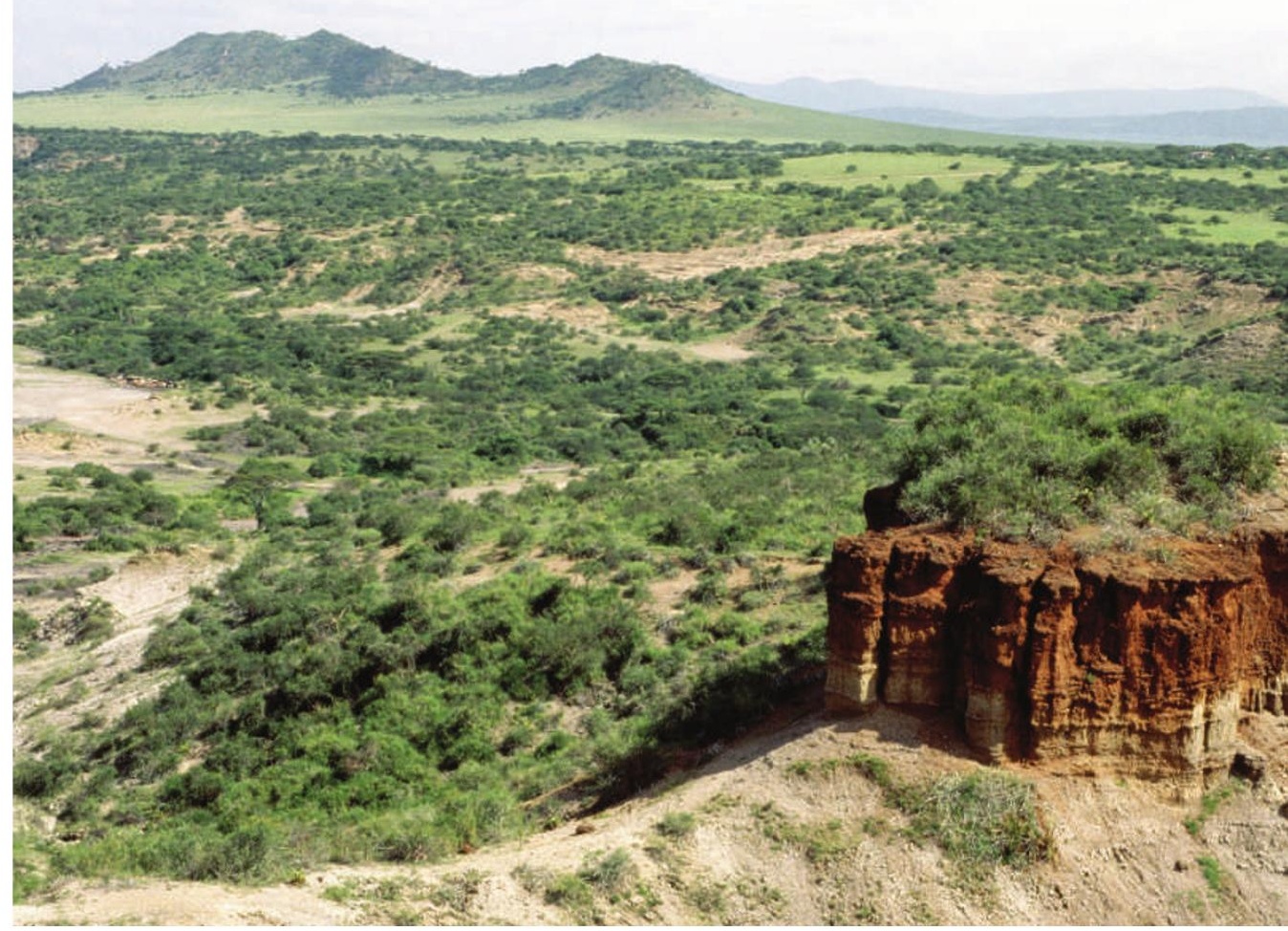

The first remains of Paranthropus boisei and Homo habilis were found at the Olduvai Gorge in Tanzania.

doubled OLAPP's grant total (US\$2 million instead of \$1 million), said that OLAPP had published only two articles (a project bibliography notes 32 articles, 8 book chapters and 12 graduate theses) and accused OLAPP leaders of "unethical behaviour" by blocking them using "political influence".

The OLAPP researchers summarized the charges in their abstract for the first East African Association of Palaeoanthropology and Palaeontology Conference, which leading researchers attended on 18-20 June in Nairobi, Kenya. In their abstract, the OLAPP researchers wrote that DomínguezRodrigo falsely accused them of "bribing Tanzanian officials" and characterized the competing group's approach as "antagonistic, unethical, uncollegial and counterproductive”.

But the OLAPP leaders did not attend the meeting, instead rushing into the field in June to monitor the site as the competing group arrived, having received new permits. The OLAPP group sent a letter to the Nairobi meeting on 17 June, apologizing for not attending and petitioning attendees to "renounce" the competing group and to support the OLAPP's call for "an apology and retraction of allega- tions". But the meeting's organizers decided that in the interests of fairness the letter would not be read to attendees.

In a phone interview from Olduvai last week, Domínquez-Rodrigo said an apology wasn't necessary. There was no specific accusation of vi "bribery", he said, but of "unethical behaviour and interfering in local politics". He declined to elaborate on these charges so as not to interfere with ongoing negotiations.

"We've taken all the measures we could to avoid conflict," he said. "The situation is awkward for both groups." Last week the two teams agreed to cohabit for the season to come.

Domínguez-Rodrigo says he wants "to enlarge the area where Leakey excavated", applying modern techniques to analyse stone tools and fossils. The 50th anniversary of Zinj's discovery is coming, and Domínguez-Rodrigo has a book being published.

John Kimaro, a Tanzanian antiquities officer overseeing Olduvai, says the government is considering guidelines for such situations, in which it seeks to maximize researcher access.

Meanwhile, observing researchers hope the years of research on 'the hallowed ground' of the Zinj fossils aren't harmed in the fray. Rex Dalton 